\title{
Differences in Science American College Testing Scores between Traditional and Alternative Science Sequences
}

\author{
John Gilbert ${ }^{1}$, James Concannon ${ }^{2 *}$ \\ ${ }^{1}$ Principal, Rich Hill, Missouri, USA, ${ }^{2}$ Director for the School of Education and Program Manager for STEM Education, William Woods University, \\ Fulton, Missouri, USA
}

*Corresponding Author: James.Concannon@williamwoods.edu

\section{ABSTRACT}

To examine differences between sequences of secondary science courses on achievement on science high stakes exams, a purposive quantitative research design was utilized in this study. A short survey was sent out to public high schools in the state of Missouri that asked to identify their main science course sequence. In addition, participants were asked to indicate if they had altered their science course sequence between the years of 2012 and 2017. This data were compared to their average building science American College Testing (ACT) score for the 2015-2016 and 2016-2017 school years in which all 16-17-year-olds in the state were required to take the exam. The analysis of the results found no connection between science course sequence and performance on the science section of the ACT for either year. In addition, it was found that schools that indicated that they altered their science course sequence had no difference in performance on the science portion of the ACT. Further research is needed to determine if there are any benefits to altering a science course sequence.

KEY WORDS: secondary science, teaching sequence, quantitative analysis, longitudinal study

\section{INTRODUCTION}

S cience education did not become part of the United States (US) high school's curriculum until the Committee of Ten recommendations at the end of the $19^{\text {th }}$ century (DeBoer, 2000). Broadly put, the recommendations emphasized that biological aspects be taught first, followed by chemistry and physics (DeBoer, 2000). The birth of the "traditional" science course sequence is still present in modern science curriculums today (Mays, 2016).

The latest change with respect to secondary science course sequence is the placement of physics first with the intent that students learn the fundamental laws of science through physics and build on them in chemistry and biology (Mason, 2002). Critics of this order claim that physics is the most important, and for that reason it needs to be taught last to stress the importance of the subject (Bretz et al., 2002). Although there are logical arguments for teaching physics first or last, the literature does not agree upon which produces higher student achievement. Some research claims there is no difference, while other research claims teaching physics to 15 -year-olds do produces better results in student achievement (Ballard, 2015; Gaubatz, 2013; Mary, 2015; Meyers, 2014; Williams, 2009). With varying findings in the literature, many schools do not find making the transition in course sequence worth the obstacles they will encounter (Larkin, 2016).

For example, Bridges (2017) compared college-readiness test scores, benchmarks for college and career-readiness, and students' interests in Science, Technology, Engineering, and Mathematics (STEM) between students who took a traditional science sequence versus the Physics First program sequence (Bridges, 2017). Findings indicate that students who took the Physics First program sequence scored higher on the American College Testing (ACT), were 1.28 times likely to meet the ACT science college- and career-readiness benchmarks, and were 1.37 times as likely to express interest in STEM (Bridges, 2017). Conversely, Meyers (2014) utilized hierarchical liner modeling to determine that science course sequence had no effect on biology end-of-course (EOC) assessment scores.

The intent of this research study was to expand on what is currently known about the impact of science course sequence on student achievement. A second purpose was to determine the effects of changing science course sequence on student achievement. The data collected were used to answer four research questions:

\section{Research Question One}

Are there any statistically significant differences in average science 2015-2016 or 2016-2017 ACT scores between schools that had a traditional science sequence versus alternative path sequences? If yes, what is the difference?

\section{Research Question Two}

Are there any statistically significant differences in 2015-2016 or 2016-2017 average science ACT scores between schools that changed science course sequence versus schools that had 
not change science course sequence between the years of 2012 and 2017? If yes, what is the difference?

\section{Research Question Three}

Are there any statistically significant differences in the frequency of schools that increased or decreased their science ACT scores from the 2015-2016 school year to the 2016-2017 school year between traditional and alternative science course sequences? If yes, what is the difference?

\section{Research Question Four}

Are there any statistically significant differences in the frequency of schools that increased or decreased their science ACT scores from the 2015-2016 school years to the 2016-2017 school years between schools that changed their science sequence versus schools that had not changed their sequence? If yes, what is the difference?

\section{Significance of the Study}

Arguably, science should be considered one of the four core subject areas in education. To prepare a student for a society that is becoming more STEM driven, it is vital for students to acquire a sound foundation in the fundamentals of secondary science (Kaliski and Godfrey, 2014). The skills students learn and acquire can be transferred to future careers in STEM related fields, such as the innovation and medical sectors. However, the current demand for certain science-based careers is not being met (Nicholas, 2014; Xue and Larson, 2015). Another concern is that prior studies show only a third of US students are enrolled in a full science sequence, and the course sequence is not universal (Nicholas, 2014). Given that the literature is mixed on which sequence of science courses in high school is the most successful in respect to student achievement on science high stakes exams, there was a need for further investigation into this topic. A full science sequence has shown greater interest and achievement in the field, but demographic gaps exist. Yet at the same time, there are many obstacles to overcome when switching the order of a high school science sequence; however, those obstacles would be worthwhile if student achievement increases (Larkin, 2016; Mays, 2016).

\section{LITERATURE REVIEW}

Today, the three sciences that are ingrained into high schools across the US are biology, chemistry, and physics (Mays, 2016). With these three being the main courses of any high school curriculum, the order of which they have been taught has remained static for several decades. The traditional order in which these courses have been taught is biology, then chemistry, and finally physics (Mays, 2016). One could argue that the traditional science sequence originated from the Committee of Ten. When biology was considered an essential piece of science education by the Committee of Ten, it was considered more of a descriptive subject (Vazquez, 2006). The original idea of biology included sub-topics as zoology, botany, and physiology requiring mostly memorization and little scientific reasoning (Vazquez, 2006). Because of the notion that chemistry and physics would require higher levels of mathematics, biology became popularized as the preferred course of most secondary schools (Sheppard and Robbins, 2003).

Before the US Civil War, approximately half of the 5-19 years old Caucasian population in the US was enrolled in school (Snyder, 1993). It was much lower for all other races, below 5\% combined (Snyder, 1993). However, enrollment sharply increased after the emancipation of slaves and continued to increase steadily for all races over the $20^{\text {th }}$ century to over $90 \%$ (Snyder, 1993). With this increase in enrollment, biology became the preferred science required from all students (Sheppard and Robbins, 2003). Tertiary institutions began requiring one secondary science credit as an entrance requirement, which further propelled biology as the first required subject (Mays, 2016).

In the 1940s, science education was at a crossroads in society. On the one hand, the Yearbook Committee of the National Society for the Study of Education linked science education to human progress, a thought that had been at the center of science education for quite some time (DeBoer, 2000). However, due to World War II, society had seen the destructive side of science, and was wary about its ability to destroy society (DeBoer, 2000). However, this societal concern had a flip side that was science could foster US national security (DeBoer, 2000).

Despite the philosophical purposes and aims of science education across decades, biology, chemistry, and physics have been traditionally taught separately in the US (Corcoran et al., 2009). This is drastically different to many of our foreign counterparts who integrate these subjects by scaffolding curriculum over several years (Corcoran et al., 2009). Although this integrated strategy has shown promising results, the likelihood of such an overhaul in the US is unlikely (Corcoran et al., 2009). Interestingly, long ago Robinson (1960) posited that the traditional US sequence is not ordered by logic because the subjects are not building on one another. Later, Haber-Schaim (1984) explained biology did not necessarily need to be taught first. Although these studies are dated, they do shine light into the culture of science education and that their historical sequence has been in question for some time.

In more recent studies, the argument of sequence has seemed to point toward a physics first approach. This is echoed in Project Arise's report indicating a physics-chemistry-biology sequence was more logical with biology being a capstone level course (Biological Sciences Curriculum Study, 2006). More recent ideas of the three courses suggest that physics is the foundational science and chemistry is the central science which leads into chemistry being the natural prerequisite for biology (Mason, 2002; More, 2007). Behind every model found in chemistry, there needs to be a simple and observable concept that physics can provide (Mason, 2002). However, there are critics to the science sequence beginning with physics. Douglas Giancoli is a physicist and stated that he, and all physicists, view the atom differently than chemists (Bretz et al., 2002). 
He stressed that physics should be taught last so students can see the ideas in chemistry and biology and then have the ideas explained using physics (Bretz et al., 2002).

However, there is research that supports that an alternative course sequence produces higher student achievement. One such study conducted by Bridges (2017) showed positive results for a Physics First approach. Williams (2009) found similar results. In a casual-comparative study, Williams examined groups of students who were in both honors and regular level courses were compared between course sequences. The study found that there was not a significant difference in academic growth between the regular and honors level students, but there was a statistical significance between the groups based on course sequence with the Physics First sequence showing more growth (Williams, 2009). The study also compared gender differences as well, and found no differences in this regard (Williams, 2009).

However, there are additional sequences that are possible when it comes to science course order. A study done by Bermudez (2014) compared the impact science course sequence had on the achievement of students on the California Standards Tests in Physics and Chemistry. The two sequences in comparison were the traditional sequence versus a biology, physics, and then chemistry sequence. Differences were found, but they were not attributed to the course sequence (Bermudez, 2014).

\section{METHODOLOGY}

To address the research questions, a purposive quantitative research design was utilized. This study utilized ex post facto research, a method of utilizing data after the fact in which there is no interference from the researcher (Silva, 2010). Average 2015-2017 science ACT scores for each secondary school were obtained from state archived records. Comparisons between schools that indicated a traditional science sequence and an alternative science sequence were made utilizing the archival data. Similarly, average science ACT scores were compared between schools who had changed their science course sequence and schools who had not changed their sequence. Finally, comparisons were made examining the frequency of schools performing better or worse on the science ACT between 2015 and 2017 based on their science sequence and alteration of their science sequence.

A short survey was sent out to public secondary school principals asking to identify their main science course sequence. In addition, participants were asked to indicate if they had altered their science course sequence between the years of 2012 and 2017. From the responses, schools were coded as traditional or alternative. Traditional science course sequence was defined as physical science, biology, chemistry, and physics (may or may not include physics). Any deviation from the traditional sequence was determined to be an alternative sequence. Alternative path sequence also included schools whereby most students did not take one specific science sequence path (multi-path).

\section{Participants}

The research sample consisted of 45 secondary school principals from 45 separate secondary schools, respectively. Secondary schools had an average of 389 students during the 2015-2016 school years, with a range of 66-1651 students. Each principal responded to the science course sequence questionnaire indicating the secondary school's respective science course sequence and indicated if they have switched their science course sequence between the years of 2012 and 2017. These responses served as the independent variables. Before responding to the survey, school principals agreed to serve in the study by indicating consent on the informed consent document approved by the William Woods University Institutional Review Board (IRB).

\section{Instrument}

Average science ACT scores were calculated and published by the State Department of Education. The ACT measures secondary students' content knowledge and provides information to colleges and universities about how to advise, place, and retain students (Atria Convergence Technologies, 2017). The ACT science portion measures the student's ability to interpret, analyze, evaluate, and problem-solve different scenarios that represent the natural world (Atria Convergence Technologies, 2017).

The ACT benchmark for the science portion of the ACT is a 23 (Atria Convergence Technologies, 2017). In addition, the ACT has been found to be both valid and reliable. The exam demonstrates reliability by measuring what it intends to measure (Lunenburg and Irby, 2008). The ACT is valid by utilizing the following resources: Subject-matter experts, research on skill targets, sequencing of skills, and student understanding that is collected from the test, the ACT National Curriculum Survey( , and survey of standards frameworks (Atria Convergence Technologies, 2017). Reliability is measured for the ACT using scale score reliability estimates and standard error of measurements (SEM) (Atria Convergence Technologies, 2017). A reliability estimate that is close to 1.0 demonstrates high reliability, and the science portion of the test for the 2015-2016 academic year had a median of 0.85 while the SEM for the science portion had a median of 2.01 (Atria Convergence Technologies, 2017).

\section{Data Collection}

After obtaining IRB approval, communication was sent to several district superintendents. An introductory message to each superintendent provided information an opportunity to not be included in the study. After communication with cooperating superintendents, a survey was electronically disseminated to secondary principals. The survey responses provided information regarding the independent variables, which were science sequence and alteration of science sequence. The survey explicitly included a statement asking principals to confirm that they desired to contribute to the study. Those that decided to participate were informed that their schools would 
remain anonymous, that participation was voluntary, and that the data would be kept confidential.

Once surveys were returned, we recorded the average ACT science scores to schools with alternative or traditional science sequences, and to schools that did or did not alter their science coursework sequence since 2012. To ensure confidentiality, codes were employed to link the school survey results to average science ACT scores. The coding did not have any information specific to school name or location; therefore, no schools could be identified.

\section{Data Analysis}

Data analyses were dependent on the research question and data collected. The independent variables, science sequence, and altering course sequences, are categorical. Average science ACT scores were treated as interval data. Defining average ACT scores increasing or decreasing from 1 year to the next was treated as categorical data. Based on the data collected and research question asked, beyond descriptive statistics an independent $t$-test was performed to answer research questions one and two and a Chi-square for independent samples was performed to answer research questions three and four.

\section{RESULTS}

There was not a significant difference in average science 2015-2016 ACT score between secondary schools utilizing traditional science course sequences $(19.70 \pm 1.36)$ and alternative science course sequences $(20.08 \pm 1.91)$ (Table 1), $\mathrm{t}(43)=-0.77, \mathrm{P}=0.45$. The mean difference between a traditional and alternative science course sequence was -0.38 . The variances were not significantly different $(\mathrm{F}=0.77$, $\mathrm{P}=0.29$ ). Average science ACT scores appeared normally distributed; however, there was an overall positive skew and positive kurtosis.

There was not a significant difference in 2016-2017 average science ACT scores between traditional science course sequences $(19.58 \pm 1.33)$ and alternative science course sequences $(19.89 \pm 1.79)$ (Table 2$), \mathrm{t}(43)=-0.66, \mathrm{P}=0.52$. The mean difference between a traditional and alternative science course sequence was -0.31 . The variances between the groups were not significantly different $(F=1.59, \rho=0.21)$.

To investigate, if there was a significant difference in average science ACT scores between secondary schools that changed

\begin{tabular}{lcccc}
\hline \multicolumn{5}{l}{ Table 1: Group statistics } \\
\hline 2015-2016 school year \\
\hline Course sequence & $\boldsymbol{n}$ & Mean & Std. deviation & Std. error mean \\
\hline Traditional & 23 & 19.70 & 1.36 & 0.28 \\
Alternative & 22 & 20.08 & 1.91 & 0.41 \\
\hline
\end{tabular}

\begin{tabular}{lcccc}
\hline \multicolumn{5}{l}{ Table 2: Group statistics } \\
\hline 2016-2017 school year \\
\hline Course sequence & $\boldsymbol{n}$ & Mean & Std. deviation & Std. error mean \\
\hline Traditional & 23 & 19.58 & 1.33 & 0.28 \\
Alternative & 22 & 19.88 & 1.79 & 0.38 \\
\hline
\end{tabular}

their primary science course sequence versus building that had not changed science sequence, an independent $t$-test was performed. There was not a significant difference in 2015-2016 average science ACT scores between secondary schools that altered their primary science course sequence $(19.64 \pm 1.74)$ and secondary schools that did not alter their primary science course sequence $(20.39 \pm 1.35), \mathrm{t}(43)=-1.48, \mathrm{P}=0.15$. Similarly, there was not a significant difference in 2016-2017 average science ACT scores between secondary schools that altered their primary science course sequence $(20.01 \pm 1.70)$ and secondary schools that did not alter their primary science course sequence $(19.61 \pm 1.30), \mathrm{t}(43)=0.35, \mathrm{P}=0.73$.

The next analysis focused on frequencies of schools that had increased or decreased on the science portion of the ACT between 2015 and 2017 based on respective science course sequence. A Chi-square test was conducted to find any statistical significance between the two groups. The Chi-square test of independence showed that there was no significant difference in the frequency of schools with increased or decreased ACT scores based on science course sequence between the 2015-2016 and 2016-2017 school years, $X^{2}$ $(1)=0.24, P=0.63$.

The last analysis determined that there was no statistically significant difference in the frequency of schools that increased or decreased average science ACT scores between schools that did or did not change their science course sequence between the years of 2012 and $2017, \mathrm{X}^{2}(1)=1.67, \mathrm{P}=0.20$. This supports the previous findings that science course sequence has no statistically significant influence on performance on the science portion of the ACT during the 2015-2016 and 2016-2017 school years.

\section{DISCUSSION}

The literature is not in agreeance on whether the differing science course sequences produce higher student achievement. Some studies have shown that an alternate science course sequence is favorable compared to the traditional sequence. Bridges (2017) compared the traditional science course sequence to a Physics First approach. He explored achievement on college-readiness test scores, benchmarks for college and career-readiness, and the participants' interest in STEM (Bridges, 2017). Students enrolled in a Physics First scored, significantly higher on the ACT, were 1.28 times more likely to meet the ACT science college- and career-readiness benchmarks, and expressed 1.37 times greater interest in STEM compared to students who were enrolled in a traditional science course sequence (Bridges, 2017). Williams (2009) also found a statistical difference between course sequences whereby students enrolled in Physics First scored higher on the ACT and the Illinois standardized science test (Williams, 2009).

The hope of addressing student achievement by changing course sequence fell short in other studies. For example, Mary (2015) did not find statistical significance in achievement on the Texas EOC scores for biology, chemistry, or physics 
(Mary, 2015). Another study performed in Missouri showed no improvement on biology EOC scores between buildings that utilized differing science course sequences (Meyers, 2014). Similarly, the current study does not support altering secondary science course sequences with the intent that this will positively impact building level science ACT scores.

\section{Implications}

The present study may offer insight for school districts altering their science course sequences within their buildings. This study not only found no statistical significance between science course sequences but it also found no statistical significance between buildings that had altered their science course sequence between the years of 2012 and 2017. The complications that come from a major change to a master schedule are not producing a significant change in performance on the science section of the ACT. Such complications include coordinating freshman level physics with freshman level algebra and a decline in students taking secondary biology (Larkin, 2016). The results suggest that these complications can be avoided by continuing to utilize their current science course sequence. On the flip side, though altering science sequences may have little to no effect on student achievement, there are some considerations that should be considered. For example, it may be the case that sequence is less important than ensuring there is alignment among science courses to Next Generation Science Standards Crosscutting Concepts and that Crosscutting Concepts are taught with fidelity to provide students a progression, distinction, and connection across all 4 -years of secondary science (NGSS Lead States, 2013). The differences among various findings in the literature may reflect the context of each study. In education, all too often it seems great initiatives begin but are not followed through to the end due to time barriers or resource constraints.

\section{Future Research}

Although the effects of science course sequence have mixed results, it is worth noting why students do not take physics. The course is considered the base science by many, and all other sciences must follow the laws of physics, but many students do not take the course. In a study done by Hadzigeorgiou and Schulz (2017), 219 students were asked why they decided to take or not take physics. This was a mixed method study that was in questionnaire form and trends were found quantitatively. The main trends for students not taking physics pointed to questions regarding its usefulness. If students did not see value in the course, they were not apt to take it (Hadzigeorgiou and Schulz, 2017).

A decreasing number of students taking physics can also be contributed to the social structure of our society. In a study done by Masood (2014), the areas of mathematics and physics are losing their popularity because they are areas that require more time commitment, focused study, regularity, rigorous training, and aptitude. This concern is not only at the secondary level but also the post-secondary as well. Many universities offer introductory level physics as a degree requirement for many other areas of study but there has been a serious decrease in physics majors (Masood, 2014). With these low numbers, universities are spending considerable time and resources on recruitment and it is not producing great results (Masood, 2014). Furthermore, many physics departments are dwindling or being absorbed by other departments and less time and resources are spent on physics (Masood, 2014). This again continues the cyclic pattern of physics not being taken, not being considered interesting, and the number of individuals in the field decreasing. Some possible avenues for future research may be exploring if a physics first approach translates into more students entering physics or physics-related college majors (e.g., Mechanical Engineering).

\section{Limitations}

Several limitations may impact the ability to generalize the results. First, limitation of how the study was designed. The research method used an independent variable that could not be changed from student to student. This is known as ex post facto and the science course sequence cannot be manipulated for an individual to see if a different outcome would occur. The dependent variable, building student achievement, utilized archival data which was also a limitation. This study analyzed the test scores to find trends in the independent and dependent variables. The dependent variable could have been affected by many other factors other than high school science course enrollment. These factors included middle school science curriculum, competency of staff both in primary and secondary education, test taking abilities of the students, test taking settings, and percentage of student transfers from another school. This study was also limited by only 45 schools participating.

\section{REFERENCES}

Atria Convergence Technologies ACT. (2017). The ACT® Technical Manual. Available from: https://www.act.org/content/dam/act/unsecured/ documents/ACT_Technical_Manual.pdf.

Ballard, Q.L. (2015). College and Career Readiness: Access to Advanced Mathematics and Science Courses in Virginia Public High Schools. (Doctoral Dissertation). Ann Arbor, Michigan: ProQuest Dissertations \& Theses Global Database.

Bermudez, J.V. (2014). Examining the Effects of Physics Second on High School Science Achievement. (Doctoral Dissertation). Ann Arbor, Michigan: ProQuest Dissertations \& Theses Global Database.

Biological Sciences Curriculum Study. (2006). The Cornerstone-toCapstone Approach. Creating Coherence in High School Science. Colorado Springs CO: Biological Sciences Curriculum Study.

Bretz, M., Thomas, I., \& Giancoli, D. (2002). Physics first: Of insight, pool balls, stasis, and the scientist in the crib. Physics Today, 55, 72-73.

Bridges, J.P. (2017). Preparing Historically Underserved Students for STEM Careers: The Role of an Inquiry-Based High School Science Sequence Beginning with Physics. (Doctoral dissertation). Ann Arbor, Michigan: ProQuest Dissertations \& Theses Global Database.

Corcoran, T., Mosher, F., \& Rogat, A. (2009). Learning Progressions in Science: An Evidence-Based Approach to Reform. CPRE Research Report \# RR-63. Philadelphia, PA: Consortium for Policy Research in Education.

DeBoer, G. (2000). Scientific literacy: Another look at its historical and contemporary meanings and its relationship to science education reform. Journal of Research in Science Teaching, 37(6), 582-601.

Gaubatz, J. (2013). Evaluation of a secondary school science program 
inversion: Moving from a traditional to a modifified-PCB sequence. Science Educator, 22(1), 19-25.

Haber-Schaim, U. (1984). High school physics should be taught before chemistry and biology. The Physics Teacher, 22(5), 330-332.

Hadzigeorgiou, Y., \& Schulz, R. (2017). What really makes secondary school students "want" to study physics? Education Sciences, 7(4), 84.

Kaliski, P.K., \& Godfrey, K.E. (2014). Does the Level of Rigor of a High School Science Course Matter? An Investigation of the Relationship between Science Courses and First-Year College Outcomes. Newtown, PA: College Board.

Larkin, D.B. (2016). Putting physics first: Three case studies of high school science department and course sequence reorganization. School Science and Mathematics, 116(4), 225-235.

Lunenburg, F.C., \& Irby, B.J. (2013). Writing a Successful Thesis or Dissertation: Tips and Strategies for Students in the Social and Behavioral Sciences. Thousand Oaks, CA: Corwin Press.

Mary, M. T. (2015). An Investigation of the Impact of Science Course Sequencing on Student Performance in High School Science and Math. (Doctoral dissertation). Ann Anbor, Michigan: ProQuest Dissertations $\&$ Theses Global Database.

Mason, D. (2002). Articulations: A case for "physics first". Journal of Chemical Education, 79(12), 1393.

Masood, S.S. (2014). How to control a decrease in physics enrollment? Available from: https://www.arxiv.org/ftp/arxiv/ papers/1405/1405.6442.pdf.

Mays, J.A. (2016). A brief history of the B-C-P sequence. Novare Science and Math, 7(2), 1-4.

Meyers, J.L. (2014). The influence of the physics first course sequence on Missouri students' biology end of course assessment. (Doctoral dissertation). Ann Anbor, Michigan: ProQuest Dissertations \& Theses Global Database.

More, M. (2007). Terra firma: "Physics first" for teaching chemistry to preservice elementary school teachers. Journal of Chemical Education, $84(4), 622-625$.

NGSS Lead States. (2013). Next Generation Science Standards: For States, by States. Washington, DC: The National Academies Press.

Nicholas, C.M. (2014). Communicating the benefits of a full sequence of high school science courses. (Doctoral Dissertation). Ann Arbor, Michigan: ProQuest Dissertations \& Theses Global Database.

Robinson, J.T. (1960). Developing a science sequence. School Science and Mathematics, 60(533), 685-692.

Sheppard, K., \& Robbins, D.M. (2003). Physics Last: A Historical Study of the Development of the US High School Science Sequence. Available from: https://www.files.eric.ed.gov/fulltext/ED474718.pdf.

Silva, C. (2010). Ex post facto study. In: Salkind NJ, editor. Encyclopedia of Research Design. Thousand Oaks, CA: SAGE Publications Limited. pp. 466.

Snyder, T.D. (1993). 120 Years of American Education: A Statistical Portrait. Available from: https://www.nces.ed.gov/pubs93/93442.pdf.

Vazquez, J. (2006). High school biology today: what the committee of ten did not anticipate. CBE Life Science Education, 5(1), 29-33.

Williams, C. (2009). Impact of Physics First on PSAE Achievement in Science and Math. Ann Arbor, Michigan: ProQuest Dissertations and Theses Global Database.

Xue, Y., \& Larson, R. (2015). STEM crisis or STEM surplus? Yes and yes. Monthly Labor Review, 138(5), 1-14. 